\title{
LEISHMANIOSE: UM CASO CLÍNICO
}

Ana Paula BONOTTO, Carolina Lupi GONÇALVES, Gabriela SANTIN, Keila RODRIGUES, Neli PIERALISI

A leishmaniose é provocada por parasitas do gênereo Leishmania. e os sintomas mais comuns são lesões cutâneas, febre e mal-estar. O diagnóstico é feito pela observação laboratorial dos parasitas presentes nas lesões, ou através de testes como a dermorreação de Montenegro, ELISA e imunofluorescência indireta. Este trabalho relata o caso de uma paciente, leucoderma, 15 anos, que queixava-se de uma lesão na gengiva, com dor e sangramento.No exame clínico, observou-se uma lesão ulcerativa, na região de incisivos centrais superiores, de $1,5 \mathrm{~cm}$. Na anamnese relatou que teve leishmaniose há cinco anos, mas fora tratada. Foi realizada biópsia no local da lesão. Os exames radiográficos panorâmico e periapical, não apresentaram alterações. Foram solicitados exames laboratoriais, dermorreação de Montenegro e imunofluorescência indireta. Na Reação de Montenegro o resultado foi positivo, assim como a imunofluorescência indireta e a biópsia. $O$ teste micológico direto e cultura para fungos foram negativos. Comprovou-se que a lesão era resultado de recidiva de leishmaniose e a paciente foi encaminhada para um médico. Concluímos que, em casos de úlceras bucais em pacientes com história prévia de leishmaniose, deve ser considerada sua recidiva. Exames laboratoriais devem ser realizados com complemento do exame clínico e radiográfico.

Palavras-chave: Leishmaniose; Biópsia; Leishmaniose Mucocutânea. 